\title{
Improved Glycemic Control Achieved by Switching to Insulin Degludec in Insulin-Treated Patients with Type 2 Diabetes in a Real-World Setting: a Non-interventional, Retrospective Cohort Study
}

\author{
Cheli Melzer Cohen • Brian Larsen Thorsted • Michael Lyng Wolden • \\ Gabriel Chodick · Avraham Karasik
}

Received: June 13, 2017 / Published online: September 7, 2017

(C) The Author(s) 2017. This article is an open access publication

\begin{abstract}
Introduction: Retrospective cohort study evaluating the clinical effectiveness of insulin degludec (IDeg) in insulin-treated patients with type 2 diabetes switching from other insulins to IDeg in a real-world setting.

Methods: Data were drawn from the Maccabi Health Management Organization in Israel and included patients treated with IDeg between 1 September 2014 and 29 February 2016. Main inclusion criteria were age $\geq 18$ years, diagnosis of type 2 diabetes, and treated with insulin for
\end{abstract}

Enhanced content To view enhanced content for this article go to http://www.medengine.com/Redeem/ 88FBF0604B838B98.

Electronic supplementary material The online version of this article (doi:10.1007/s13300-017-0297-9) contains supplementary material, which is available to authorized users.

C. Melzer Cohen · G. Chodick

Medical Division, Maccabi Healthcare Services, Tel Aviv, Israel

B. L. Thorsted · M. L. Wolden

Novo Nordisk A/S, Søborg, Denmark

G. Chodick · A. Karasik

Sackler Faculty of Medicine, Tel Aviv University, Tel Aviv, Israel

A. Karasik $(\bowtie)$

Department of Endocrinology, Sheba Medical

Center, Tel Hashomer, Israel

e-mail: karasik@tau.ac.il at least 1 year prior to IDeg initiation. HbA1c, insulin dose, body weight, and body mass index were recorded before and 90 and 180 days post-switch.

Results: Of 211 eligible patients, 57\% were male, mean age $\pm \mathrm{SD} \quad 62.2 \pm 12.1$ years, and diabetes duration $>10$ years. Switching to IDeg decreased $\mathrm{HbA1c}$ from a mean $8.8 \pm 1.5 \%$ $(73.0 \pm 16.4 \mathrm{mmol} / \mathrm{mol})$ baseline by $0.58 \pm$ $1.0 \%(6.3 \pm 10.9 \mathrm{mmol} / \mathrm{mol})(p<0.001)$. Baseline $\mathrm{HbA} 1 \mathrm{c}$ of $>8.5 \%(69.0 \mathrm{mmol} / \mathrm{mol})$ and daily insulin dose of $\geq 50 \mathrm{U}$ were associated with a greater reduction in HbA1c $[1.0 \pm 1.1 \%$ $(10.9 \pm 12.0 \mathrm{mmol} / \mathrm{mol})$ and $1.2 \pm 1.1 \%$ $(13.1 \pm 12.0 \mathrm{mmol} / \mathrm{mol})$, respectively] compared with the total population. At 180 days post-switch, the mean daily basal insulin dose increased by $2 \mathrm{U}$ compared with pre-switch. There was no significant change in body weight post-switch.

Conclusions: In a real-world setting, switching from another insulin to IDeg significantly improved glycemic control in patients with type 2 diabetes, without significant weight gain and with only a modest increase in insulin dose after IDeg initiation.

Funding: Novo Nordisk.

Keywords: Basal; Degludec; Dose; Glycemic control; Insulin; Real-world data 


\section{INTRODUCTION}

Insulin is recommended as a pivotal therapy in the treatment of patients with advanced type 2 diabetes by European Association for the Study of Diabetes and American Diabetes Association guidelines [1]. However, despite its unsurpassed efficacy in lowering blood glucose concentrations, a significant proportion of patients fail to reach target HbA1c levels after starting basal insulin therapy $[2,3]$. In recent years, alternative approaches to extending the time-action profile of basal insulins have been developed with the aim of improving glycemic control and specifically reducing the risk of hypoglycemia [4-9].

Although randomized controlled trials (RCTs) are an essential requirement for assessing the safety and efficacy of new therapeutic agents compared with existing treatment options, they have limitations due to their trial design, inclusion/exclusion criteria, and highly selected patient populations. RCTs that evaluate insulin formulations often use the treat-to-target approach. The foremost limitation of this approach is that any difference in end-of-trial HbA1c between treatment arms will be minimal by design to allow the accurate assessment of the impact on other areas, e.g., rates of hypoglycemia or insulin dose requirement [10]. Real-world data-data on effectiveness drawn from clinical practice-can complement RCTs by closing gaps in knowledge regarding pharmacologic performance in a real-world patient population.

Insulin degludec (IDeg) is a basal insulin with a unique mode of protraction, which provides an ultra-long duration of action ( $>24 \mathrm{~h}$ ) and four times lower variability in blood glucose-lowering activity compared with insulin glargine (IGlar) U100 [4-8]. Data from RCTs in patients with type 2 diabetes have shown that IDeg reduces the risk of hypoglycemia compared with IGlar U100, can improve the quality of life of patients, and provides the potential for flexibility in dose timing if necessary, provided a minimum interval of $8 \mathrm{~h}$ between doses is maintained [11-13]. In addition, post hoc analyses have shown that patients treated with IDeg have a significantly lower total daily insulin dose requirement compared to IGlar U100 [11, 12, 14-19].
The primary objective of the present study was to examine the clinical effectiveness of switching from other insulin treatments to IDeg in patients with type 2 diabetes. Secondary objectives included describing any changes in body weight, body mass index (BMI), and insulin dose after switching to IDeg.

\section{METHODS}

This non-interventional, retrospective cohort study utilized de-identified data from the central computerized databases of the Maccabi Health Management Organization (HMO), which is the second largest HMO in Israel, covering over 2 million patients. It is estimated to include 100,000 patients with type 2 diabetes whose complete medical data are recorded in a central diabetes registry [20]. This registry is comprehensive, with information on all patient interactions (diagnoses, visits to primary and secondary care physicians, visits to outpatient clinics, hospitalizations, laboratory tests, and purchased and dispensed medications). In addition, the Maccabi HMO database has developed and validated computerized registries of its patients with major chronic diseases, such as ischemic heart disease, hypertension, and oncologic diseases [21-23]. The Maccabi HMO database is thus ideally suited for studying the real-world use and clinical effectiveness of IDeg.

The present study included patients treated with IDeg between 1 September 2014 and 29 February 2016. The index date was defined for each patient as the first date of purchase of IDeg. The pre-treatment period was defined as -180 to 0 days prior to the index date. The follow-up period was defined as 90-270 days after the index date (measurements made $180 \pm 90$ days after the index date). Patients meeting the inclusion criteria were $\geq 18$ years old with type 2 diabetes according to the diabetes registry of Maccabi $\mathrm{HMO}$, treatment with insulin prior to starting IDeg (which was defined as at least three purchases of insulin in the 365 days prior to the index date), continuous treatment with IDeg for $\geq 180$ days, and had at least one HbA1c measurement during both the pre-IDeg and follow-up periods. Diagnosis of type 2 diabetes was made 
Table 1 Population demographics and baseline characteristics

\begin{tabular}{|c|c|c|c|}
\hline Parameter & Category & $n(\%)$ & Mean \pm SD (median) \\
\hline \multirow[t]{2}{*}{ Sex } & Male & $126(57.0)$ & - \\
\hline & Female & $95(43.0)$ & - \\
\hline Age, years & Mean \pm SD (median) & $62.2 \pm 12.1(63.4)$ & - \\
\hline \multirow[t]{5}{*}{$\mathrm{HbAlc}, \%(\mathrm{mmol} / \mathrm{mol})$} & - & - & $8.8 \pm 1.5(8.6)$ \\
\hline & & & {$[73.0 \pm 16.4(70)]$} \\
\hline & $<7.5 \%(<58)$ & $33(14.9)$ & - \\
\hline & $7.5-8.5 \%(58-69)$ & $76(34.4)$ & - \\
\hline & $>8.5 \%(>69)$ & $112(50.7)$ & - \\
\hline \multirow[t]{5}{*}{ BMI $\left(\mathrm{kg} / \mathrm{m}^{2}\right)$} & - & - & $29.0 \pm 5.2(28.5)$ \\
\hline & $\leq 30$ & $111(50.2)$ & - \\
\hline & $30-35$ & $48(21.7)$ & - \\
\hline & $>35$ & $18(8.1)$ & - \\
\hline & Unknown & $44(19.9)$ & - \\
\hline Weight (kg) & - & - & $81.5 \pm 15.1(81.0)$ \\
\hline \multicolumn{4}{|l|}{ Comorbid condition $^{\mathrm{a}}$} \\
\hline CVD major disease & Yes & $56(25.3)$ & - \\
\hline Carlson comorbidity score & - & - & $2.4 \pm 1.4(2.0)$ \\
\hline \multicolumn{4}{|c|}{ Use of anti-diabetes medications ${ }^{\mathrm{b}}$} \\
\hline Metformin & Yes & $132(59.7)$ & - \\
\hline SU & Yes & $33(14.9)$ & - \\
\hline DPP-4i & Yes & $62(28.1)$ & - \\
\hline GLP-1RA & Yes & $57(25.8)$ & - \\
\hline SGLT2-i & Yes & $3(1.4)$ & - \\
\hline Other & Yes & $45(20.4)$ & - \\
\hline \multicolumn{4}{|l|}{ Type of insulin } \\
\hline Short acting & Yes & $9(4.1)$ & - \\
\hline Basal & Yes & $82(37.1)$ & - \\
\hline Basal bolus & Yes & $122(55.2)$ & - \\
\hline Premix & Yes & $8(3.6)$ & - \\
\hline
\end{tabular}

$B M I$ body mass index, $C V D$ cardiovascular disease, DPP- $4 i$ dipeptidyl peptidase-4 inhibitor, GLP-1RA glucagon-like peptide-1 receptor agonist, $S D$ standard deviation, $S G L T 2-i$ sodium-glucose co-transporter 2 inhibitor, $S U$ sulfonylurea

${ }^{a}$ CVD major disease classified according to the ICD-9 codes: ischemic heart disease, myocardial infarction, congestive heart failure, peripheral vascular disease, cerebrovascular disease, transient ischemic attack, atrial fibrillation, prior coronary artery bypass grafting, or percutaneous coronary intervention

b At least two medication dispenses within 180 days pre-index date. All patients were pre-treated with other insulin prior to index date 
using the age and treatment regimen of the patient at entry into the registry. Patients were excluded if they left Maccabi HMO during the study period (180 days before the index date to 270 days after the index date), became pregnant, or died during the study period. HbA1c, insulin dose (total and basal), body weight, and BMI were recorded at baseline and during follow-up. Insulin dose was also recorded in the pre-switch period.

\section{Statistical Analyses}

Population demographics and baseline characteristics were reported using descriptive statistics [mean \pm standard deviation (SD) for continuous parameters and number of patients and percentage for categorical parameters]. Continuous and ordinal variables were compared using a paired Student's $t$ test or Wilcoxon signed-rank test as appropriate. Categorical variables were compared using a chi-square test or Fisher's exact test as appropriate. Patient number and percentage were reported for all categories, while mean, SD, and median were also reported for continuous variables. Statistical significance was defined as $p<0.05$. Correlations between variables were assessed using Spearman's and Pearson's coefficients. All statistical analyses were performed using SAS v9.2. (Cary, NC, USA) and/ or SPSS v22.0 (Armonk, NY, USA).

Individual patient informed consent was not required because of the anonymized nature of the patient records. Approval was obtained from the Institutional Review Board (IRB) and Ethics Committee of the Maccabi HMO for the purposes of accessing and analyzing the data. Furthermore, the Maccabi HMO IRB and Ethics Committees have actively accepted a waiver for individual informed consent. This article does not involve any new studies with human or animal subjects performed by any of the authors.

\section{RESULTS}

\section{Population Demographics and Baseline Characteristics}

A total of 221 eligible patients meeting the inclusion criteria were identified. Of these patients, $57.0 \%$ were male, mean age was $62.2 \pm 12.1$ years, and all had diabetes duration of $>10$ years. Mean HbA1c was $8.8 \pm 1.5 \%$ $(73.0 \pm 16.4 \mathrm{mmol} / \mathrm{mol})$ at baseline, and $55.2 \%$ of patients were on a basal-bolus regimen prior to the index date (Table 1). After IDeg initiation, the proportion of patients on insulin containing a short-acting component (short acting, basal bolus or premix insulin) decreased from $62.9 \%$ to $52.0 \%$ ( $p<0.001$; Table 2$)$.

\section{Glycemic Control}

Switching to IDeg led to a mean \pm SD decrease in $\mathrm{HbA} 1 \mathrm{c}$ of $0.58 \pm 1.0 \% \quad(6.3 \pm 10.9 \mathrm{mmol} / \mathrm{mol}$; $p<0.001)$ at 180 days compared with baseline (Fig. 1). A baseline HbA1c of $>8.5 \% \quad(69.0$ $\mathrm{mmol} / \mathrm{mol}$ ) and daily insulin dose of $\geq 50 \mathrm{U}$ were associated with a greater reduction in $\mathrm{HbA1c}$ of $1.0 \pm 1.1 \%(10.9 \pm 12.0 \mathrm{mmol} / \mathrm{mol})$ and $1.2 \pm$ $1.1 \%(13.1 \pm 12.0 \mathrm{mmol} / \mathrm{mol})$ (both $p<0.001)$, respectively, compared with the total population (data not shown). Change in HbA1c at 180 days was inversely associated with baseline HbA1c $(p<0.001)$ (Fig. S1). At 180 days, 115 patients $(52 \%)$ achieved a $\geq 0.5 \%(5.5 \mathrm{mmol} / \mathrm{mol})$ reduction in HbA1c. The proportions of patients in whom HbA1c was reduced by 0.5 to $<1.0 \%(5.5$ to $<10.9 \mathrm{mmol} / \mathrm{mol}), \quad 1.0$ to $<1.5 \% \quad(10.9$ to $<16.4 \mathrm{mmol} / \mathrm{mol})$ and $\geq 1.5 \% \quad(\geq 16.4 \mathrm{mmol}$ $/ \mathrm{mol})$ were $22.2 \%(n=49), 14.9 \%(n=33)$, and $14.9 \%(n=33)$, respectively (Fig. S1).

Table 2 Shift table of insulin regimens at baseline and during 180 days from index date

\begin{tabular}{lccc}
\hline Regimen & \multicolumn{2}{l}{$\mathbf{1 8 0}$ days post-index date } & \\
\cline { 2 - 3 } Baseline & $\begin{array}{l}\text { Basal, } \\
\boldsymbol{n}(\%)\end{array}$ & $\begin{array}{l}\text { Basal bolus, } \\
\boldsymbol{n}(\%)\end{array}$ & $\begin{array}{l}\text { Total, } \\
\boldsymbol{n}(\%)\end{array}$ \\
\hline Short acting & $0(0)$ & $9(7.8)$ & $9(4.1)$ \\
Basal & $72(67.9)$ & $10(8.7)$ & $82(37.1)$ \\
Basal bolus & $29(27.4)$ & $93(80.9)$ & $122(55.2)$ \\
Premix & $5(4.7)$ & $3(2.6)$ & $8(3.6)$ \\
Total & $106(100.0)$ & $115(100.0)$ & $221(100.0)$ \\
\hline
\end{tabular}




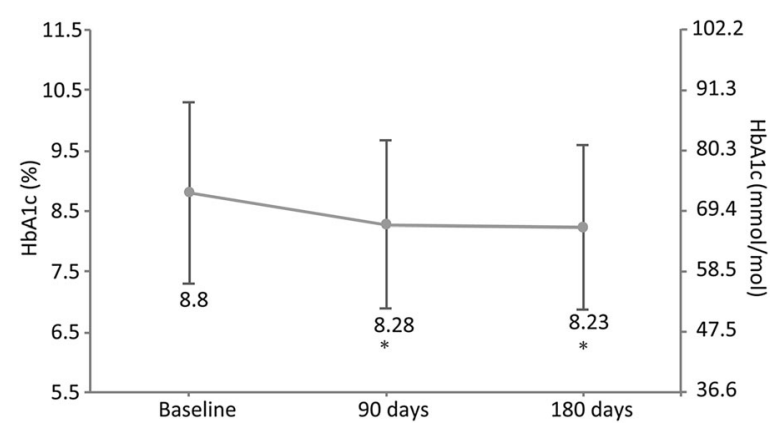

Fig. 1 Mean HbAlc over time. ${ }^{*} p<0.001$ versus baseline. Error bars are SD

\section{Insulin Dose}

Among patients treated with basal insulin during 180 days pre-index date, there was a transient increase in the mean daily basal insulin dose between 0 and 90 days, followed by a significant decrease and return to the pre-switch insulin dose in the 91 to 180-day period (Fig. 2). Overall, there was an increase of $2 \mathrm{U}$ from pre-switch to 180 days' follow-up, $(p=0.003$; data not shown $)$.

\section{Change in Body Weight and BMI}

There was no significant $(p=0.855)$ change in body weight or BMI between baseline and end of follow-up (Table 3).

\section{DISCUSSION}

This investigation using data from the Maccabi HMO database confirms that IDeg provides statistically significant and clinically meaningful improvements in glycemic control in our particular real-world population [24].

This is the largest real-world study of patients with type 2 diabetes switching to IDeg from other insulins. A recently published retrospective, single-center study by Evans et al. evaluated the clinical efficacy of switching to IDeg in a real-world population [25]. Patients $[n=51$ (35 type 1 diabetes, 16 type 2 diabetes)] were switched from insulin detemir or IGlar U100 to IDeg because of recurrent hypoglycemia/fear of hypoglycemia, difficulty with injections, excessive variability in blood glucose concentrations, or problems with adhering to a strict injection schedule. After a mean follow-up of $25.5 \pm 6$ weeks, HbA1c was improved by $0.5 \%$ $(5.5 \mathrm{mmol} / \mathrm{mol})$ in patients with type 1 diabetes and $0.7 \%(7.7 \mathrm{mmol} / \mathrm{mol})$ in those with type 2 diabetes. Insulin dose was increased by $7.1 \mathrm{U}$ for patients with type 1 diabetes and $10.7 \mathrm{U}$ in those with type 2 diabetes; however, the mean rate of hypoglycemic episodes per week decreased by $>90 \%$. Body weight remained stable [25]. A larger real-world study by Landstedt-Hallin et al. in patients with type 1 diabetes $(n=357)$ demonstrated that switching to IDeg improved $\mathrm{HbA} 1 \mathrm{c}$ by $0.3 \%(3.3 \mathrm{mmol} / \mathrm{mol})$, while the insulin dose was reduced by $12 \%$ [26]. Switching to IDeg was also associated with a $20 \%$ reduction in the rate of overall hypoglycemia and a halving of the rate of nocturnal hypoglycemia [26]. Notably, the reduction in HbA1c after 6 months of treatment with IDeg was higher in our study than in the prospective study of Shimoda et al.; however, differences in study design, such as active follow-up of participants, may have contributed to this observation [27].

The findings of the present study support those of Evans et al. and Landstedt-Hallin et al., in which HbA1c was reduced after switching to IDeg $[25,26]$. The reduction in HbA1c with only a minimal increase in insulin dose is of clinical importance, as is the absence of an increase in body weight. Clinically relevant reductions in $\mathrm{HbA} 1 \mathrm{c}$ are usually a result of up-titrating the insulin dose, which leads to an increase in BMI [28]. The reduction in HbA1c could be due to physicians setting lower blood glucose targets due to a reduced concern over the risk of hypoglycemia, or patients' adherence may have improved because of reduced fear of experiencing a hypoglycemic event [29]. Although not assessed in the present study, patients may also be more adherent to their treatment regimen because of its potential for flexibility in dose timing. However, these findings should be viewed in the context of the study population, which was previously insulin-treated, with many patients on basal-bolus regimens and a large proportion with HbA1c $>8.5 \%(69 \mathrm{mmol} / \mathrm{mol})$. Indeed, those patients with the poorest glycemic control exhibited 


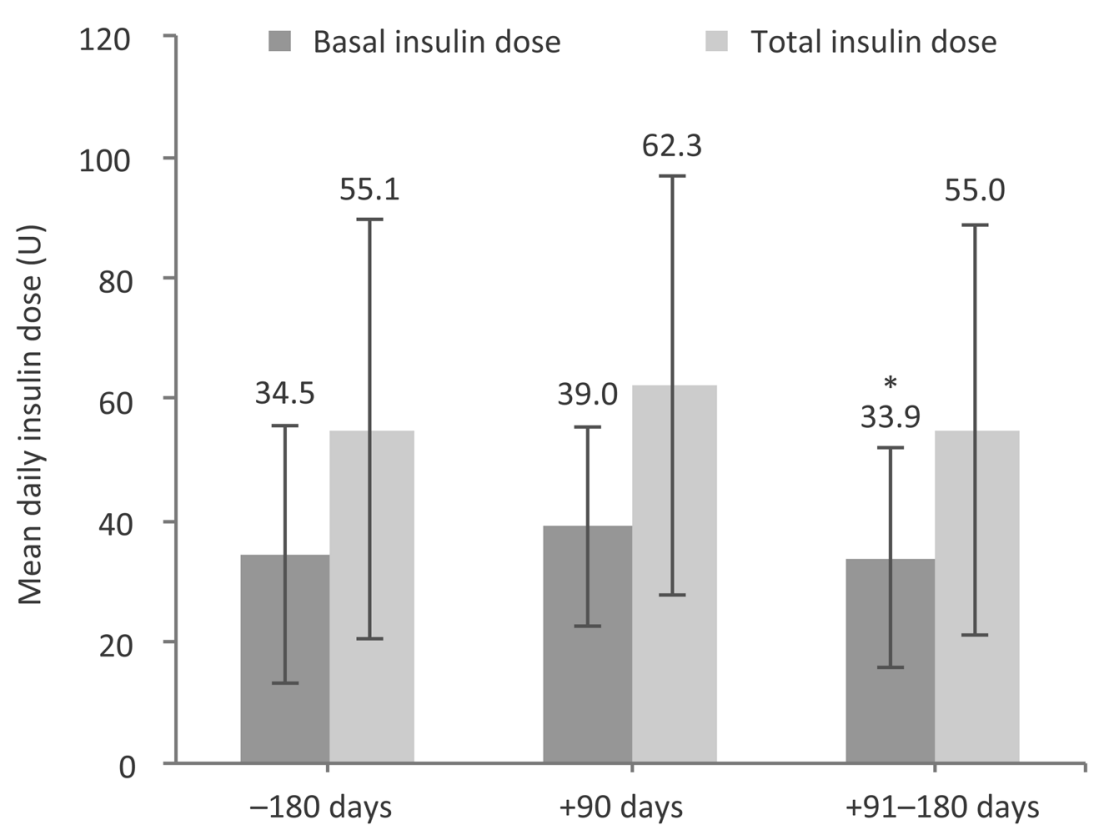

Fig. 2 Mean insulin dose before and after switching to IDeg. Error bars are SD; -180 days of recording was taken before switching to IDeg; +90 and $+91-180$ days of

recordings were taken after switching to IDeg. ${ }^{*} p<0.001$ versus +90 days. $I D e g$ insulin degludec

Table 3 Body weight and BMI at baseline and 180 days post-index date

\begin{tabular}{llllllll}
\hline Parameter & Period & Mean & SD & Median & $\boldsymbol{N}$ & $\boldsymbol{p}$ value & 95\% CI \\
\hline Weight $(\mathrm{kg})$ & Baseline & 81.5 & 15.1 & 81.0 & 178 & & \\
& 180 days post-index date & 81.1 & 13.8 & 80.1 & 155 & & \\
& Change & -0.1 & 3.5 & 0.0 & 123 & 0.855 & -0.7 to 0.6 \\
BMI $\left(\mathrm{kg} / \mathrm{m}^{2}\right)$ & Baseline & 29.0 & 5.2 & 28.5 & 177 & & \\
& 180 days post-index date & 29.0 & 4.7 & 28.4 & 155 & & \\
& Change & -0.0 & 1.3 & 0.0 & 123 & 0.802 & -0.3 to 0.2 \\
\hline
\end{tabular}

$B M I$ body mass index, $C I$ confidence interval, $S D$ standard deviation

the greatest reduction in $\mathrm{HbA1c}$, suggesting that IDeg may have clinical benefits even among those who are maximally titrated on basal insulin. Furthermore, the magnitude of improvement in glycemic control after switching to IDeg is similar to that observed in patients switching from neutral protamine Hagedorn (NPH) to IGlar U100 [30]. The clinical consequences of reducing $\mathrm{HbA} 1 \mathrm{c}$ by $0.58 \%$ $(6.3 \mathrm{mmol} / \mathrm{mol})$ are significant. For example, the UK Prospective Diabetes Study (UKPDS) showed that, for every $1 \%(10.9 \mathrm{mmol} / \mathrm{mol})$ of reduction in $\mathrm{HbA1c}$, there is a relative risk reduction of $21 \%$ for any diabetes-related endpoint, $21 \%$ for diabetes-related deaths, $14 \%$ for myocardial infarction, and $37 \%$ for microvascular complications [31]. Regardless of whether the improvement in glycemic control after switching to IDeg is pharmacologic or a result of switching to a new basal insulin, IDeg provides clinicians with another treatment option that yields real clinical improvements, and the results of the present study may have a positive impact on the prescribing behavior of clinicians and on the self-management of patients. 
The present study is subject to limitations that warrant mention. These include the observational nature of the study and lack of a comparator arm, which have the potential to introduce bias and confounding into the analysis. There is also the risk of misclassification of diabetes type; however, we do not have any reason to believe that this would be a major problem in the study population. The short duration of follow-up in this study prohibits any extrapolation of the observations to the long term, where other factors such as progressive beta-cell decline or loss of patients' motivation in adhering to a new therapy may lead to a reversal of improvements in glycemic control. In addition, there is the potential for selection bias in the patients switched to IDeg. Furthermore, the absence of safety data should be considered when interpreting these findings, in particular the rate of hypoglycemia, as this is closely related to HbA1c and is a key clinical benefit of IDeg in the phase 3 trial program $[14,18,19]$. Using real-world data, this study was only able to capture documented hypoglycemic events-those that came to medical attention. Thus, this study cannot be effectively used to assess the effect of therapy on rates of hypoglycemic events. In contrast, the strengths of the present analysis include the large realworld patient population and high levels of completeness of data in the registry.

\section{CONCLUSION}

In summary, this retrospective study of realworld data from the Maccabi HMO demonstrates that switching from another insulin to IDeg significantly improves glycemic control in patients with type 2 diabetes, without causing weight gain and with only a modest increase in mean daily basal insulin dose after switching.

\section{ACKNOWLEDGEMENTS}

Novo Nordisk provided funding to Maccabi Healthcare Services to carry out the analysis. No funding was provided for author participation in the writing or review of the manuscript.
Article processing charges were funded by Novo Nordisk. The authors acknowledge medical writing assistance from Paul Tisdale, PhD, and editorial support from Germanicus Hansa-Wilkinson and Helen Marshall of Watermeadow Medical, UK (sponsored by Novo Nordisk). All authors had full access to all of the data in this study and take complete responsibility for the integrity of the data and accuracy of the data analysis. All named authors meet the International Committee of Medical Journal Editors (ICMJE) criteria for authorship for this manuscript, take responsibility for the integrity of the work as a whole, and have given final approval to the version to be published. CMC, BLT, MLW, GC, and AK contributed to the study design, data analysis and interpretation, drafting, review, and approval of the manuscript. AK is the guarantor of this work and, as such, had full access to all the data in the study and takes responsibility for the integrity of the data and the accuracy of the data analysis.

Disclosures. Brian Larsen Thorsted is an employee of and shareholder in Novo Nordisk A/S Søborg, Denmark. Michael Lyng Wolden is an employee of and shareholder in Novo Nordisk A/S Søborg, Denmark. Avraham Karasik has received research grants, honoraria, and consultation fees from Novo Nordisk, AstraZeneca, and Boehringer Ingelheim. Cheli Melzer Cohen and Gabriel Chodick have nothing to disclose.

Compliance with Ethics Guidelines. Individual patient informed consent was not required because of the anonymized nature of the patient records. Approval was obtained from the Institutional Review Board (IRB) and Ethics Committee of the Maccabi Healthcare Services for the purposes of accessing and analyzing the data. Furthermore, the Maccabi Healthcare Services IRB and Ethics Committees have actively accepted a waiver for individual informed consent. This article does not involve any new studies with human or animal subjects performed by any of the authors.

Data Availability. The data sets analyzed during the current study are not publicly available because of the ethics committee approval 
process for database studies in Israel, under which only specific researchers are permitted to access the data.

Open Access. This article is distributed under the terms of the Creative Commons Attribution-NonCommercial 4.0 International License (http://creativecommons.org/licenses/ by-nc/4.0/), which permits any noncommercial use, distribution, and reproduction in any medium, provided you give appropriate credit to the original author(s) and the source, provide a link to the Creative Commons license, and indicate if changes were made.

\section{REFERENCES}

1. Inzucchi SE, Bergenstal RM, Buse JB, et al. Management of hyperglycemia in type 2 diabetes, 2015: a patient-centered approach: update to a position statement of the American Diabetes Association and the European Association for the Study of Diabetes. Diabetes Care. 2015;38:140-9.

2. Curtis B, Lage MJ. Glycemic control among patients with type 2 diabetes who initiate basal insulin: a retrospective cohort study. J Med Econ. 2014;17:21-31.

3. Dale J, Martin S, Gadsby R. Insulin initiation in primary care for patients with type 2 diabetes: $3--$ year follow-up study. Prim Care Diabetes. 2010;4:85-9.

4. Jonassen I, Havelund S, Hoeg-Jensen T, Steensgaard DB, Wahlund PO, Ribel U. Design of the novel protraction mechanism of insulin degludec, an ultra-long-acting basal insulin. Pharm Res. 2012;29:2104-14.

5. Steensgaard DB, Schluckebier G, Strauss HM. Ligand-controlled assembly of hexamers, dihexamers, and linear multihexamer structures by the engineered acylated insulin degludec. Biochemistry. 2013;52:295-309.

6. Kurtzhals P, Heise T, Strauss HM. Multi-hexamer formation is the underlying basis for the ultra-long glucose-lowering effect of insulin degludec. Diabetologia. 2011;54(Suppl. 1):S426.

7. Heise T, Nosek L, Bøttcher SG, Hastrup H, Haahr H. Ultra-long-acting insulin degludec has a flat and stable glucose-lowering effect in type 2 diabetes. Diabetes Obes Metab. 2012;14:944-50.
8. Heise T, Hermanski L, Nosek L, Feldman A, Rasmussen S, Haahr H. Insulin degludec: four times lower pharmacodynamic variability than insulin glargine under steady-state conditions in type 1 diabetes. Diabetes Obes Metab. 2012;14:859-64.

9. Rosenstock J, Diamant M, Aroda VR, et al. Efficacy and safety of LixiLan, a titratable fixed-ratio combination of Lixisenatide and insulin glargine, versus insulin glargine in type 2 diabetes inadequately controlled on metformin monotherapy: the LixiLan proof-of-concept randomized trial. Diabetes Care. 2016;39:1579-86.

10. White RD. The treat-to-target alC approach to control type 2 diabetes and prevent complications. Adv Ther. 2007;24:545-9.

11. Meneghini L, Atkin SL, Gough SC, et al. The efficacy and safety of insulin degludec given in variable once-daily dosing intervals compared with insulin glargine and insulin degludec dosed at the same time daily: a 26-week, randomized, open-label, parallel-group, treat-to-target trial in individuals with type 2 diabetes. Diabetes Care. 2013;36:858-64.

12. Mathieu C, Hollander P, Miranda-Palma B, et al. Efficacy and safety of insulin degludec in a flexible dosing regimen vs insulin glargine in patients with type 1 diabetes (BEGIN: Flex T1): a 26-week randomized, treat-to-target trial with a 26-week extension. J Clin Endocrinol Metab. 2013;98:1154-62.

13. Novo Nordisk. Tresiba ${ }^{\circledR}$ summary of product characteristics. 2015: http://www.ema.europa.eu/docs/ en_GB/document_library/EPAR_-_Summary_for_the_ public/human/002498/WC500138964.pdf. Accessed Sep 2016.

14. Ratner RE, Gough SC, Mathieu C. Hypoglycaemia risk with insulin degludec compared with insulin glargine in type 2 and type 1 diabetes: a pre-planned meta-analysis of phase 3 trials. Diabetes Obes Metab. 2013;15:175-84.

15. Vora J, Christensen T, Rana A, Bain SC. Insulin degludec versus insulin glargine in type 1 and type 2 diabetes mellitus: a meta-analysis of endpoints in phase 3a trials. Diabetes Ther. 2014;5:435-46.

16. Freemantle N, Evans M, Christensen T, Wolden ML, Bjorner JB. A comparison of health-related quality of life (health utility) between insulin degludec and insulin glargine: a meta-analysis of phase 3 trials. Diabetes Obes Metab. 2013;15:564-71.

17. Freemantle N, Meneghini L, Christensen T, Wolden $\mathrm{ML}$, Jendle J, Ratner R. Insulin degludec improves health-related quality of life $\left(\mathrm{SF}-36^{\circledR}\right)$ compared with insulin glargine in people with type 2 diabetes starting on basal insulin: a meta-analysis of phase 3a trials. Diabet Med. 2013;30:226-32. 
18. Lane WS, Bailey TS, Gerety G, et al. Effect of insulin degludec vs insulin glargine U100 on hypoglycemia in patients with type 1 diabetes: The SWITCH 1 randomized clinical trial. JAMA. 2017;318:33-44.

19. Wysham $\mathrm{CH}$, Bhargava A, Chaykin LB, et al. Effect of insulin degludec vs insulin glargine U100 on hypoglycemia in patients with type 2 diabetes: the SWITCH 2 randomized clinical trial. JAMA. 2017;318:45-56.

20. Chodick G, Heymann AD, Shalev V, Kookia E. The epidemiology of diabetes in a large Israeli HMO. Eur J Epidemiol. 2003;18:1143-6.

21. Heymann A, Chodick G, Halkin H, et al. The implementation of managed care for diabetes using medical informatics in a large preferred provider organization. Diabetes Res Clin Pract. 2006;71:290-8.

22. Heymann A, Maor Y, Goldstein I, et al. Efficacy of liraglutide in a real-life cohort. Diabetes Ther. 2014;5:193-206.

23. Shalev V, Chodick G, Goren I, Silber H, Kokia E, Heymann AD. The use of an automated patient registry to manage and monitor cardiovascular conditions and related outcomes in a large health organization. Int J Cardiol. 2011;152:345-9.

24. Little RR, Rohlfing CL. Sacks DB; National Glycohemoglobin Standardization Program (NGSP) Steering Committee. Status of hemoglobin A1c measurement and goals for improvement: from chaos to order for improving diabetes care. Clin Chem. 2011;57:205-14.

25. Evans M, McEwan P, Foos V. Insulin degludec early clinical experience: does the promise from the clinical trials translate into clinical practice-a case-based evaluation. J Med Econ. 2015;18:96-105.
26. Landstedt-Hallin L. Changes in HbA1c, insulin dose and incidence of hypoglycemia in patients with type 1 diabetes after switching to insulin degludec in an outpatient setting: an observational study. Curr Med Res Opin. 2015;31:1487-93.

27. Shimoda S, Sato M, Sekigami T, et al. A 1-year, prospective, observational study of Japanese outpatients with type 1 and type 2 diabetes switching from insulin glargine or detemir to insulin degludec in basal-bolus insulin therapy (Kumamoto Insulin Degludec Observational study). J Diabetes Investig. 2016;7:703-10.

28. Garber AJ, King AB, Del Prato $S$, et al. Insulin degludec, an ultra-longacting basal insulin, versus insulin glargine in basal-bolus treatment with mealtime insulin aspart in type 2 diabetes (BEGIN Basal-Bolus Type 2): a phase 3, randomised, open-label, treat-to-target non-inferiority trial. Lancet. 2012;379:1498-507.

29. Peyrot M, Barnett AH, Meneghini LF, Schumm-Draeger PM. Insulin adherence behaviours and barriers in the multinational global attitudes of patients and physicians in insulin therapy study. Diabet Med. 2012;29:682-9.

30. Sharplin P, Gordon J, Peters JR, Tetlow AP, Longman AJ, McEwan P. Improved glycaemic control by switching from insulin NPH to insulin glargine: a retrospective observational study. Cardiovasc Diabetol. 2009;8:3.

31. Stratton IM, Adler AI, Neil HA, et al. Association of glycaemia with macrovascular and microvascular complications of type 2 diabetes (UKPDS 35). BMJ. 2000;321:405. 